\title{
Atividades em sala de aula
}

Ruth Ribas Itacarambi

Doutora pela Faculdade de Educação da USP. Educadora aposentada do IME-USP. Coordenadora do Grupo Colaborativo de Investigação em Educação Matemática (GCIEM). Professora do curso de pós-graduação da Faculdade Oswaldo Cruz. Membro da Equipe SiteEducacional.

E-mail: acarambi@usp.br

"Estamos passando de uma sociedade com sistema educativo para uma sociedade do conhecimento $e$ aprendizagem contínua. Assim o que outrora foi um lugar de densa socialização converteu-se em um espaço cada vez mais dedicado à administração de saberes, estes que agora os especialistas dos ministérios pretendem "modernizar" chamando-os de competências..." (Barbero, 2014) ${ }^{1}$

A organização das atividades nesta edição tem como centro os temas: Ensino Médio no Brasil, Conectividade, Representação Visual e Inclusão das Mulheres na Produção Científica.

$\mathrm{O}$ artigo de Adilson Citelli, "Reforma do ensino médio: déficit de comunicação e intercorrências políticas”, traça o panorama caótico em que a questão da reforma do ensino médio está inserida e ressalta os desencontros, quando aponta a aprovação da lei para reformar o ensino em 2017, por medida provisória (MPV 746/2016). No ano seguinte, órgãos da imprensa anunciam que o Ministério da Educação estava retirando a tramitação do documento para realizar ajustes em pontos obscuros e o Conselho Nacional de Secretários da Educação (CONSED) informa consulta pública sobre a BNCC (Base Nacional Comum Curricular). Entender o contexto da criação da proposta de reforma do Ensino Médio, para o autor, traz consigo as marcas de um país atravessado por profunda crise política e no qual as composições e alianças dirigem pautas cujo alcance diz respeito, diretamente, aos problemas de governabilidade e busca de alguma legitimação popular. Nesta direção, o artigo apresenta a leitura crítica da indicação dos ministros de educação, abordando os períodos de: 1964 a 1985, a época da ditadura; 1985 a 1992, a influência partidária como determinante; a mudança que ocorre no período Itamar Franco (1992-1995) com a presença de um professor e, de certa forma, os governos que se sucederam até a volta,

1. MARTIN-BARBERO, Jesús. A comunicação na educação. São Paulo: Contexto, 2014. p. 121 
comunicação \& educação • Ano XXIII • número 2 • jul/dez 2018

em 2017, da herança partidária, quando retornam ao Ministério escolhas que são resultado de loteamentos políticos.

Artigos desta revista, em edições anteriores, têm tratado do tema das Mídias e Educação. Nesta edição, vamos falar sobre a conectividade a partir do artigo "Conectar ou desconectar: debates sobre a reflexão a partir da Educação para os meios", de Leandro Marlon Barbosa Assis e Alexandre Farbiarz, cujo objetivo, segundo seus autores, é discutir se a melhoria do ensino nas escolas se daria a partir da introdução de tecnologias dentro do cotidiano escolar. O artigo também propõe a análise das práticas e estratégias políticas para inserir as Mídias na escola, aponta que na $\mathrm{BNCC}^{2}$ ou no novo Ensino Médio ${ }^{3}$ não se identificam as medidas para a formação da prática docente e, menos ainda, as condições de infraestrutura para o desempenho das atividades pedagógicas propostas nos textos oficiais, as quais foram colocadas, em 2018, em debate público. Os autores comentam que o debate inserido nos textos da BNCC, ou na reforma do Ensino Médio, acaba por se orientar pela dinâmica de inserção no mercado de trabalho. Para eles, o papel da escola é ser uma força capaz de potencializar a reflexão sobre a formação de identidades e, também, estabelecer os vínculos face a face com os outros membros sociais frente à fragmentação advinda das redes digitais.

Na mesma perspectiva das Mídias e Educação, temos o artigo de Maria Ogécia Drigo e Luciana Coutinho Pagliarini de Souza, "Representação visual e cognição: estudo com livros didáticos de Ciências e Matemática para o Ensino Fundamental", que tem. como propósito averiguar em que medida as representações visuais contribuem para desencadear processos cognitivos. Segundo as autoras, a reflexão é relevante para a interface comunicação/educação, pois traz à tona a possibilidade de que as disciplinas escolares sejam vistas como linguagens que, ao incorporarem signos distintos do verbal, implicam em novos conhecimentos sobre tais modalidades de representações.

A questão das mulheres na investigação crítica é objeto de análise de Sarah Corona Berkin no artigo "El aporte de las mujeres a la investigación crítica de la comunicación en América Latina”, que, segundo a autora, coincide com o novo plano para o conselho nacional de ciências e tecnologia do México. A autora não se considera defensora das mulheres, nem dos indígenas, nem dos pobres, porque esta é a forma de fomentar os estereótipos feminino e masculino, de raça e de classe social. Mas a autora quer tratar da participação das mulheres na investigação em Comunicação Social, com especial ênfase nas mulheres precursoras do campo na América Latina e a inclusão das mulheres na produção científica.

As atividades nesta edição estão organizadas pelos seguintes temas:

- O panorama político da reforma do ensino médio;

- Sociedade do conhecimento: conexão;

- Sociedade do conhecimento: imagens e representações; e

- As mulheres na produção científica. 


\section{PRIMEIRA ATIVIDADE}

\section{O panorama político da reforma do ensino médio}

O objetivo da atividade é apresentar e discutir a reforma do ensino médio que foi apresentada para consulta pública em 2018 e as interferências políticas no Ministério da Educação, que é usado como moeda de troca para o apoio dos partidos políticos, desde a época da ditadura até os dias atuais. Tem-se como referência o artigo "Reforma do ensino médio: déficit de comunicação e intercorrências políticas", de Adilson Citelli.

A atividade é recomendada para os cursos de licenciaturas das diferentes áreas do conhecimento, cursos de graduação de Comunicação e Pedagogia e para professores e alunos do ensino médio e está organizada na seguinte sequência didática:

1. Propor a leitura do artigo em grupo, solicitando que os participantes façam uma tabela identificando pelo menos um titular do Ministério da Educação em cada período apontado no artigo e seu partido de origem, de 1964 até os dias atuais. Por exemplo:

\begin{tabular}{|c|c|c|c|}
\hline Período & Ministro da Educação & Partido de origem & $\begin{array}{c}\text { Presidente do } \\
\text { Brasil }\end{array}$ \\
\hline $1966-1969$ & Pedro Aleixo & ARENA & Castelo Branco \\
\hline
\end{tabular}

Como apoio para a atividade, além do artigo, propomos consultar os sites: https://pt.wikipedia.org/wiki/Lista_de_ministros_da_Educa\%C3\%A7\%C3\%A3o_ do_Brasil

http://portal.mec.gov.br/institucional/galeria-de-ministros

2. Fazer a exposição das tabelas dos grupos e analisar os dados a partir das seguintes ideias:

- Os partidos dos personagens que encabeçam o Ministério nos diferentes períodos e governos presidenciais;

- A formação acadêmica desses ministros e as medidas pedagógicas que ocorreram no período e produziram impacto na educação.

3. A partir da tabela, propomos a análise de alguns temas e questões:

O ENEM (Exame Nacional do Ensino Médio) foi aplicado pela primeira vez em 1998 e tinha o objetivo de avaliar anualmente o aprendizado dos alunos do ensino médio em todo o país para auxiliar o Ministério na elaboração de políticas pontuais e estruturais de melhoria do ensino.

- Qual o objetivo atual do ENEM e quando e por que ocorreram as mudanças? 
A existência de uma Base Nacional Curricular Comum foi prevista na Constituição Federal, de 1988, na Lei de Diretrizes e Bases da Educação (LDB), de 1996 e no Plano Nacional de Educação (PNE), de 2014. Em 2015, começou a construção do documento, o qual tem como objetivo orientar nacionalmente a educação básica, que abrange a educação infantil, o ensino fundamental e o médio ${ }^{4}$.

- Qual é problemática da reforma do Ensino Médio?

A reforma do Ensino Médio tem seus fundamentos dirigidos por três grandes eixos: flexibilização curricular; tempo integral e ensino técnico ou formação para o trabalho. Para subsidiar o trabalho do professor, sugerimos que assista o vídeo: https://www.youtube.com/watch?v=eTowriTcNd8

4. Fazendo a leitura do artigo de Citelli, como você, aluno do ensino médio e/ou professor, interpreta cada um dos eixos, tendo como parâmetros a sua realidade escolar?

Para subsidiar a análise, propomos que os alunos assistam às mídias veiculadas pelo governo sobre a reforma do ensino médio nos links:

https://www.youtube.com/watch?v=RuF0GYgmrJQ

https://www.youtube.com/watch?v=iIszj0WWqfA

https://www.youtube.com/watch?v=P_liPX6Ui54

Fazer a síntese das questões em sala de aula, propor a redação de um documento com a opinião dos alunos e divulgar no site da escola.

5. Problemas para serem discutidos na sala dos professores:

- Primeiro, o que interfere na administração da escola e que consiste em desvendar, como o autor do artigo diz, que tipo de especialista "com notório saber" estaria disposto a aceitar a rotina de sala de aula, como é proposto no documento da base sobre o ensino médio.

- Quais políticas públicas estão sendo propostas na base para a formação inicial e continuada dos profissionais da educação, inclusive no que diz respeito aos salários e à melhoria das condições materiais de trabalho.

Fazer a ata da reunião e divulgar no site da escola ou em algum espaço coletivo.

\section{SEGUNDA ATIVIDADE}

\section{Sociedade do conhecimento: conexão}

A atividade está organizada para os cursos de graduação de Comunicação, Pedagogia, Letras, licenciaturas em geral e para professores que estão em sala de aula com alunos do ensino médio. 
Está organizada na seguinte sequência didática, para professores e alunos:

1. Leitura do artigo destacando as seguintes afirmações:

- O indivíduo desloca-se do projeto coletivo, construído pela Modernidade, para uma atuação fragmentada dentro de escolhas já pré-estabelecidas pela dinâmica econômica;

- A perspectiva de um consumo orientado à exibição e satisfação imediata se apresenta pelo volume crescente de desejos postos em um fluxo constante a partir da Cultura de Mídia; ${ }^{5}$

- A ação do sujeito pautado pela solução de problemas sociais pode ser substituída por uma prática individualista de satisfação de prazeres em nome do preenchimento do vazio que, paradoxalmente, surge da velocidade que o consumo impõe à sociedade;

- Assim, pode-se reconhecer que a sociedade contemporânea é atravessada pelas Mídias e pelas práticas de consumo oriundas das esferas sociais hegemônicas.

Fazer a síntese dos comentários em grupo, identificando os comportamentos pessoais dos alunos em relação às afirmações do artigo.

2. Os caminhos apresentados pelos autores do artigo:

- Os educandos estão inseridos ${ }^{6}$ na cultura digital e podem utilizar deste ambiente virtual para enriquecer a experiência escolar;

- Os vídeos postados em canais no YouTube ou em páginas do Facebook podem ser utilizados pelos educadores;

- A emergência de uma Educação para as Mídias como forma a contrapor o consumo irrefletido e, também, interferir na manutenção de uma dinâmica reificadora da vida social.

3. Dificuldades apontados no artigo para a implementação das ideias selecionadas acima:

- A estrutura física e o despreparo/desvalorização dos profissionais limitam o alcance de um projeto educativo diferente possibilitado pelas tecnologias;

- Como garantir aos educandos a chance de ampliarem o alcance de seu conhecimento já adquirido pela prática cotidiana, se faltam condições básicas para o funcionamento escolar.

- Como escrevem Freire e Guimarães ${ }^{7}$,

[...] falta também, muitas vezes, a nós, professores, uma atitude mais compatível com a nossa realidade, que é a de primeiro procurar aproveitar os meios simples que temos [...] e, a partir do momento em que nós estivermos conseguindo desenvolver, já artesanalmente, o conhecimento e o envolvimento das pessoas, aí poderemos também partir para os recursos industriais.

5. KELLNER, Douglas. A Cultura da Mídia: estudos culturais de identidade e política entre o moderno e o pós-moderno. São Paulo: EDUSC, 2001.

6. Cf. TIC Kids Online Brasil. Disponível em: <http:// cetic.br/pesquisa/kids-onli ne/>. Acesso em: 11 ago. 2017.

7. FREIRE, Paulo; GUIMARÃES, Sérgio. Educar com a mídia: novos diálogos sobre educação. São Paulo: Paz \& Terra, 2011. p. 104. 
4. Discutir em um grupo de professores e um outro de alunos os caminhos e as dificuldades apresentadas pelos autores e fazer uma comparação entre as visões dos alunos e as dos professores.

5. Propor a confecção de um portfólio das atividades da escola que contemplem as Mídias e analisar a conclusão do autor.

Portanto, ao reconhecermos que optar pelo uso ou não das mídias digitais acarreta perdas irreparáveis, caso não tenhamos a convicção de qual projeto de Educação queremos.

\section{TERCEIRA ATIVIDADE}

\section{Sociedade do conhecimento: imagens e representações}

O artigo de Maria Ogécia Drigo e Luciana Coutinho Pagliarini de Souza, "Representação visual e cognição: estudo com livros didáticos de Ciências e Matemática para o Ensino Fundamental”, tem o propósito de averiguar em que medida as representações visuais contribuem para desencadear processos cognitivos. Para as autoras, a onipresença da imagem em todos os níveis de representação e da psique do homem torna premente um olhar atento para este fenômeno, em particular, no ambiente escolar e nos diversos meios, como os livros didáticos.

A atividade está organizada para professores de ciências e matemática do ensino básico, fundamental e médio e seus alunos.

1. Leitura do artigo destacando os seguintes pontos:

- As imagens podem ser agregadas aos fatores que tecem as relações na sociedade contemporânea;

- Tais relações podem ser percebidas também no ambiente educacional e nos mais diversos meios, inclusive nos livros didáticos;

- Voltamos nossa atenção para imagens - representações visuais - presentes em duas coleções de livros de Ciências e duas de Matemática.

2. Discutir o significado das imagens nos livros didáticos, em particular nos livros de Ciências e de Matemática e a definição de signo proposta no artigo. 3. Segundo as autoras, as representações visuais apresentadas: fotografias, ilustrações, gráficos, tabelas, entre outras, podem ser classificadas, na perspectiva de Pierce, como signos e ser classificadas em ícone, índice e símbolo.

Discutir com os alunos a classificação de Peirce para os signos e definir o que é ícone, índice e símbolo.

Para subsidiar a discussão propomos que os alunos assistam aos vídeos abaixo. O segundo trata da Semiótica e traz as ideias de Peirce. Para nosso propósito, é recomendado assistir de 0:00 a 2:27:

https://youtu.be/a_6mVTaP-KE

https://youtu.be/VD1JM7UVjhk 
Em seguida, propor que os alunos, em grupo, façam a leitura do item: Classificação/Cognição e Representações Visuais do artigo e pesquisem em seus livros didáticos signos que podem ser classificados como ícone, índice ou símbolo, segundo a perspectiva de Peirce. Pedir para que registrem a página e a representação que foi identificada como signo.

Fazer um painel das representações escolhidas e dialogar sobre a pertinência de cada uma quanto ao fato de ser ícone ou índice ou símbolo.

Discutir com os alunos a importância das representações visuais em seus livros didáticos e como elas ajudam na compreensão dos conteúdos abordados.

Selecionar as representações dos livros didáticos que, para os alunos, foram consideradas mais significativas para a compreensão de um certo conteúdo, identificando o seu conteúdo.

\section{QUARTA ATIVIDADE}

\section{As mulheres na produção científica}

A questão das mulheres na investigação crítica é objeto de análise de Sarah Corona Berkin, no artigo "El aporte de las mujeres a la investigación crítica de la comunicación en América Latina”. A autora trata da participação delas na investigação em Comunicação Social, com especial ênfase nas precursoras do campo na América Latina e a inclusão das mulheres na produção científica.

O texto está em espanhol e o indicamos para alunos dos cursos de graduação de Jornalismo, Comunicação, Letras e História.

1. Para os alunos de graduação, pedir que façam uma lista das mulheres que costumam citar em seus trabalhos acadêmicos e/ou estão nas referências bibliográficas de seus cursos.

2. Fazer uma síntese, registrando o número de mulheres presentes na lista e comparar com o número de homens.

3. A autora escreve sobre a presença das mulheres no campo da Comunicação Social que, segundo ela:

[...] por ser un campo interdisciplinario es representativo de muchos otros y por ser relativamente nuevo es fácil rastrear sus primeras investigaciones. Hablaré del papel de las mujeres desde esos primeros trabajos de comunicación y muestro la continuidad, si bien actualizada a la fecha, de su invisibilidad.

A autora identifica três linhas de investigação que se fazia na América Latina nas décadas de 60 e 70. São elas: Crítica ao imperialismo, A Teoria da dependência do sul em relação ao norte, registrando as relações de dominação, e Comunicação popular, que é apresentada como uma opção metodológica.

4. Propor que os alunos façam a leitura do artigo e em grupo discutam as três linhas apresentadas, esclarecendo a que situações a autora se refere. Fazer a síntese das ideias apresentadas.

5. Fazer a leitura do item "Las mujeres en la academia", identificar as mulheres que são citadas e suas contribuições acadêmicas. 